\title{
Size miniaturization of chipless RFID tag using metamaterial structure
}

\author{
Mohd Ezwan B Jalil, Mohamad Kamal A. Rahim, Osman B Ayop, Noor Asmawati Samsuri \\ Advanced RF \& Microwave Research Group, School of Electrical Engineering, Faculty of Engineering, Universiti \\ Teknologi Malaysia, Malaysia
}

\begin{tabular}{l} 
Article Info \\
\hline Article history: \\
Received Oct 22, 2018 \\
Revised Jan 28, 2019 \\
Accepted Mar 3, 2019 \\
\hline
\end{tabular}

\section{Keywords:}

Chipless RFID

Metamaterial

PET substrate

Size miniaturization

Split ring resonator

\begin{abstract}
A Chipless RFID based Modified Complementary Split Ring Resonator (MCSRR) with Different Width (DW) which is metamaterial structure is designed using PET substrate $\left(\varepsilon_{r}=3\right.$, loss tangent $=0.025$ at $\left.2 \mathrm{GHz}\right)$ to miniaturize effective length size of conventional split ring resonator. The MCSRR structure with DW provides less size about $17 \%$ compared with the conventional MCSRR structure. The single MCSRR resonator with different width only requires a frequency range of $12 \%$ of Complementary Split Ring Resonator (CSRR) resonator. The slotted MCSRR resonator is located underneath substrate and within substrate is connected with transmission lines. The insertion loss value of MCSRR resonator is used to encode ID information of chipless RFID with maximizing ID information using Frequency Position technique. The best swapping parameter for encoding ID number information is split gap of both ring compare with other parameter such as spacing between ring and width of ring.
\end{abstract}

Copyright $(0) 2019$ Institute of Advanced Engineering and Science. All rights reserved.

\section{Corresponding Author:}

Mohamad Kamal A Rahim,

Advanced RF \& Microwave Research Group,

School of Electrical Engineering, Faculty of Engineering,

Universiti Teknologi Malaysia, 81310, Johor Bharu, Malaysia.

Email:mdkamal@utm.my

\section{INTRODUCTION}

Chipless Radio-Frequency Identification (RFID) is a wireless identification and tracking object system that is using electromagnetic field for short range communication without chips. The technology of chipless RFID with the integration of Internet of Thing (IOT) offers a huge potential to replace the conventional visual optical barcode especially for labeling and tracking items at the supermarket, wardrobe and storage room [1]. Unlike the visual barcode, the chipless RFID does not require the line of sight between the RFID and tag for detection. The chipless RFID is able to read the tag for greater distance with the faster rate than conventional RFID [2]. However, chipless RFID have some limitation such as low capacity data [3] and big tag size [4].

Conventional RFID consist of the reader with transceiver, tag with computerized microchip and host computer with identification application. The tag contains serial number information as unique ID for specific object. To detect unique ID number, the antenna reader transmits interrogation signal to tag using the antenna. The tag will respond to the signal by providing ID number information to the RFID reader. The chipless RFID system is introduced with removing the computerized microchip with memory information [5] as shown in Figure 1. 


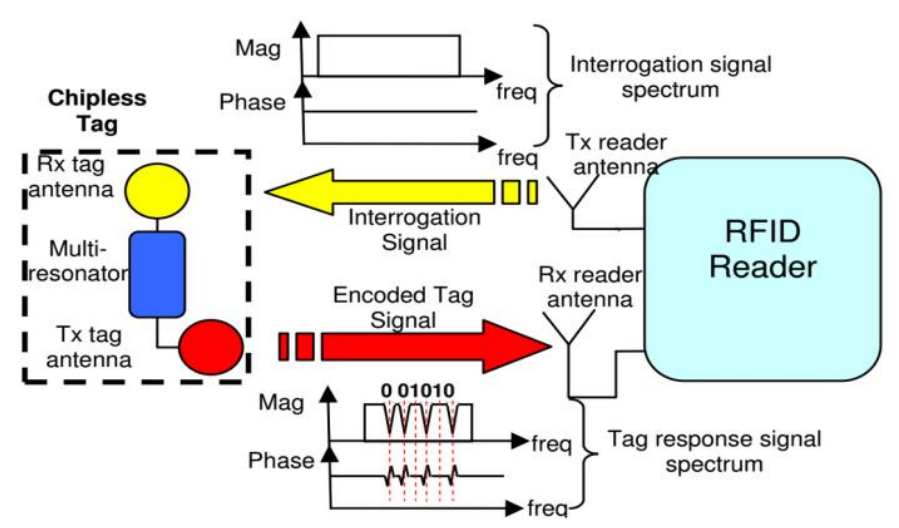

Figure 1. Chipless RFID system [11]

Compact size and high capacity are the essential criteria for developing the chipless RFID tag. Among variation chipless identification method of tag such as using time domain [5], phase [6], frequency domain [7-9] and image [10], the chipless RFID using frequency domain is capable to obtain high capacity data. From previous work, Predavovic designed 35 bit chipless RFID with 35 spiral resonator with length of $0.6 \lambda$ between 3.1 and $7 \mathrm{GHz}$ [11]. Vena introduced a potential 22.9 bit chipless RFID with 5 "C" resonators with length of $0.7 \lambda$ by using hybrid decoding technique; frequency position and phase deviation [12]. Bhuiyan has proposed coplanar waveguide chipless RFID tag using multi-Meandered Modified Complementary Split Ring Resonator structure (MCSRRR) with the capability to excite 2 resonances for each MCSRR [13]. All of the literature works regarding the way to increase the data capacity with minimal size of tag using resonator element.

In metamaterial structure, the ability of changing permittivity and permeability in electromagnetic field is required by designing the structure rather than base material. The artificial metamaterial with transforming electromagnetic properties from positive to negative delivers potential solution to fulfill demand in designing modern microwave device such as compact antenna [14], filter [15], lenses antenna [16] and sensor [17] for achieving miniaturization size [18], multi-band behavior [19] and more extraordinary performance [20-21].

This study aim is to miniaturize the size and increase the data capacity of chipless RFID tag using Modified Complementary Split Ring Resonator (MCSRR). Split Ring Resonator (SRR) is a conventional metamaterial structure consisting of double ring with different gap position. The SRR structure behaves as small LC circuit with size less than $\lambda / 2$ can be excited by axial magnetic field. The resonance change occurred due to inductive current in the ring and field inside the capacitive gap. CSRR, which represents the negative image of SRR considered as electric dipole that can be excited by axial, electric field [22]. The SRR and CSRR are reliable to produce a small resonator due to increased inductance and capacitance by adjustment of width, split gap and spacing parameter [23]. However, SRR and CSRR only produce a singular resonance in each structure. The implementation of MCSRR structure by CSRR modification increases the number resonant to enhance data capacity of chipless RFID.

In this paper, a flexible multi-resonator chipless RFID tag based on Modified Complementary Split Ring Resonator (MCSRR) with different width is presented to miniaturize the size of tag by reducing the effective length of the resonator and reducing the frequency gap between two resonators. In the following section, three proposed designs; CSRR, MCSRR and MCSRR with different width are compared and evaluated in term of size of effective and resonance frequency. Then, the parameters for analysis such as split gap of the inner ring, split gap of outer ring, spacing between rings and width of rings are investigated for determining the suitable swapping parameter to encode with ID number. A frequency position technique is introduced as coding technique. Lastly, the result between simulation and measurement of insertion loss result of 10 bit of chipless RFID based MCSRR is compared and evaluated to validate the design and the material properties.

\section{DESIGN OF MULTI-RESONATOR CHIPLESS RFID TAG}

A flexible chipless RFID tag is manufactured using Polyethylene Terephthalate (PET) substrate with permittivity of 2 , thickness of $48 \mathrm{~mm}$ and loss tangent of 0.0025 . The $0.09-\mathrm{mm}$ copper foil with the adhesive 
is used as the high conductive element of substrate. A high conductive element minimizes electrical loss and improves the performance of Q-factor resonator [24]. The specific designs presented in this section aims to achieve the miniaturization size of tag according to effective length of the resonator. To achieve the most miniature size, each resonator requires less size of effective in lambda. Next, the small frequency gap between two resonating element is required to reduce the operating frequency.

Three different designs are simulated using Computer Simulation Technology (CST Microwave Studio) 2015. There have three types slotted resonators with various structure; Complementary Split Ring Resonator (CSRR), Modified Complementary Split Ring Resonator (MCSRR) and Modified Complementary Split Ring Resonator with Different Width (MCSRR with DW) as shown in Figure 2. The slotted ground plane structures are connected with transmission line between two ports. The insertion loss between two ports will be used to encode information value depending of position of resonance frequency in the adjacent section.

The effective dielectric constant of the substrate for micro strip transmission as shown in (1) is required to predict effective length of outer and inner ring as shown in (2). The reference length of SRR and MCSRR structure is the circumference of ring with reduction of gap ring value. Basically, a short circuit using $\lambda / 2$ transmission line is acting as series resonator with high quality factor. To reduce the size of resonator, the semi lumped resonator which is electrically a small resonant element constructing by adding capacitance and inductance structures is introduced. The resonant frequency of semi lumped resonator equation is given by $\mathrm{f}=1 / 2 \pi L C$ which $\mathrm{f}$ is described as frequency, $\mathrm{L}$ is described as total inductance of resonator and $\mathrm{C}$ is described as total capacitance of resonator.

$$
\begin{aligned}
& \varepsilon_{\text {eff }}=\frac{\varepsilon_{\mathrm{r}}+1}{2}+\frac{\varepsilon_{\mathrm{r}}-1}{2}-0.217\left(\varepsilon_{\mathrm{r}}-1\right) \\
& \text { Valid only when } W_{\text {copper }} / T_{\text {substrate }}>1 \\
& \text { Effective Length }=\frac{c}{f \sqrt{\varepsilon_{\text {eff }}}}
\end{aligned}
$$

$\mathrm{c}=$ speed of light

$\mathrm{f}=$ frequency

$\varepsilon_{r}=$ relative permittivity

Circumference of ring $=2 \pi r-g$

$\mathrm{R}=$ radius of ring

$\mathrm{g}=$ gap of ring

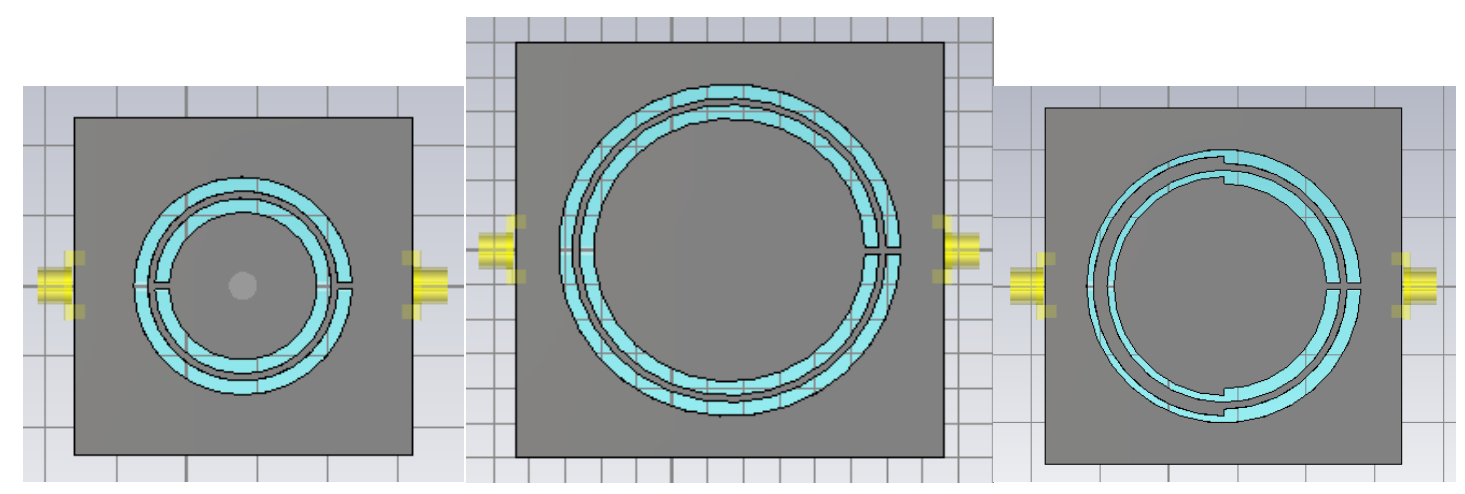

Figure 2. Proposed multi-resonator structure; A) CSRR structure, B) MCSRR structure C) MCSRR with different width

In designing high capacity data of chipless RFID, the single structure should maximize amount number resonator and consider minor separation between resonance frequencies. Figure 3 demonstrate the evolution of the MCSRR with DW from CSRR resonator aiming for frequency gap reduction between two resonances and size miniaturization of the inner ring and outer ring. For all the designs, the first resonance is determined between $0.87-0.88 \mathrm{GHz}$ and all parameter is fixed including the split gap between the ring, 
the spacing between the ring and the width of rings. From the result, the SRR resonator with length of 0.365 $\lambda$ is $27 \%$ smaller compared with the conventional $\lambda / 2$ resonator. However, the length of second resonant frequency of SRR with $0.845 \lambda$ is $69 \%$ larger than conventional $\lambda / 2$ resonator. The frequency allocation depends on range frequency between two resonators. From the result, the MCSRR resonator only requires a frequency range of $8 \%$ of CSRR resonator for two rings. Comparison between split ring resonators as shown in Table 1.

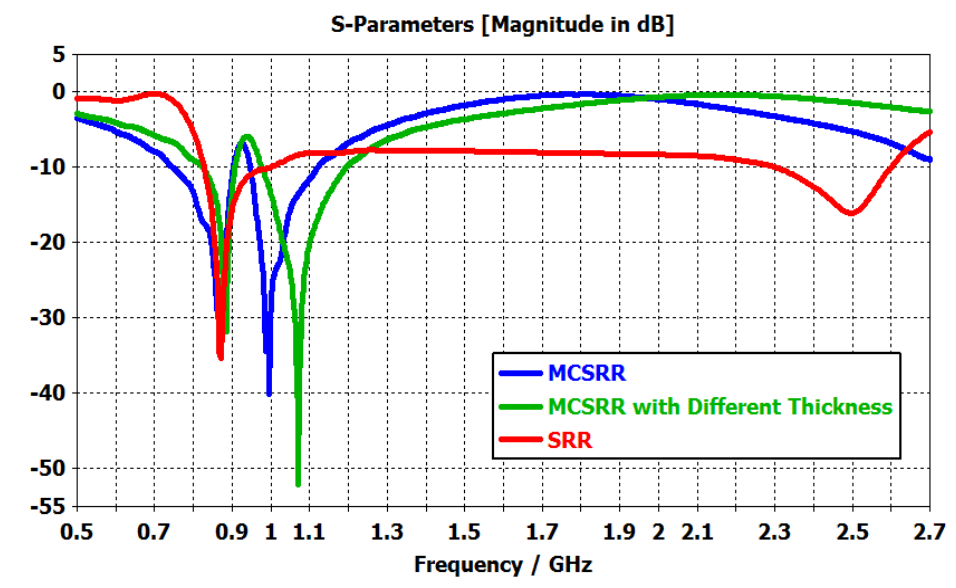

Figure 3. The simulated $S_{21}$ insertion loss for the proposed design; SRR (red), MCSRR (blue), MCSRR

Table 1. Comparison between Split Ring Resonators

\begin{tabular}{|c|c|c|c|c|c|c|}
\hline \multirow[t]{3}{*}{ Types } & \multicolumn{3}{|c|}{ Length of First Outer Ring } & \multicolumn{3}{|c|}{ Length of Second Inner Ring } \\
\hline & $\mathrm{mm}$ & $\lambda$ & Resonance & $\mathrm{Mm}$ & $\lambda$ & Resonance \\
\hline & & & Frequency & & & Frequency \\
\hline $\begin{array}{l}\text { Complementary Split Ring } \\
\text { Resonator }\end{array}$ & 96.39 & 0.365 & 0.87 & 77.54 & 0.845 & 2.50 \\
\hline $\begin{array}{l}\text { Modified Complementary Split } \\
\text { Ring Resonator }\end{array}$ & 149.80 & 0.568 & 0.87 & 130.95 & 0.571 & 1.00 \\
\hline $\begin{array}{c}\text { Modified Complementary Split } \\
\text { Ring Resonator with different } \\
\text { thickness }\end{array}$ & 124.66 & 0.480 & 0.88 & 105.81 & 0.493 & 1.07 \\
\hline
\end{tabular}

In order to reduce the electrical size of the second inner ring but keep at the low length of first outer ring, the MCSRR is introduced by adjusting the split gap with the same position. The length of inner ring MCSRR is reduced about $32 \%$ compared with the CSRR resonator. The inner and outer rings of MCSRR structure have the length less than $0.572 \lambda$. To miniaturize the size of MCSRR structure, the width of MCSRR is divided into two. The width of gap section is thicker than the other side of MCSRR. The MCSRR structure with DW achieves size reduction of $17 \%$ compared with previous MCSRR structure. From the result, the single MCSRR resonator with different width only requires a frequency range of $12 \%$ of CSRR resonator.

\section{RESULTS AND ANALYSIS}

In this section, the effect of the main parameter of MCSRR with different width is analyzed including split gap of outer ring, split gap of inner ring, spacing between rings and width of ring. During parameter study, only one parameter is altered while other parameter will remain unchanged to clarify the effect of each parameter on the performance of insertion. The reference diagram of MCSRR with different width structure is shown in Figure 4. The relationship between split gap of outer ring and insertion loss is shown in Figure 5. The resonant frequency of the outer ring is proportional to the parameter of split gap of outer ring. The resonant frequency of the fixed inner ring is unchanged when split gap of outer ring above 1.0 $\mathrm{mm}$. The width of transmission line is fixed at $1.3 \mathrm{~mm}$. 


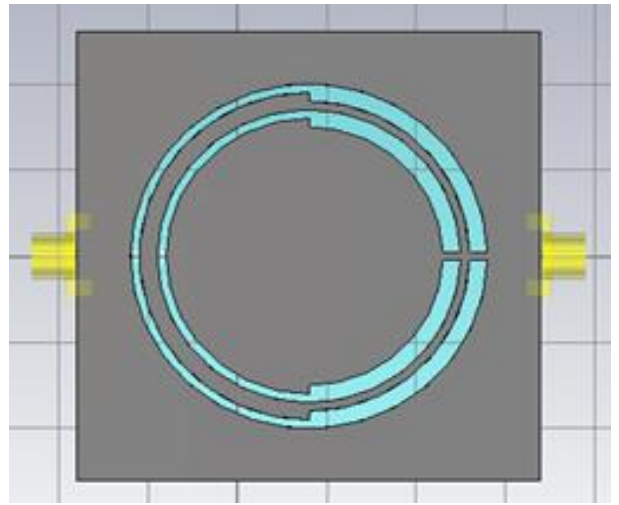

Figure 4. CSRR structure with dimension (split gap of ring $=1.0 \mathrm{~mm}$, width of ring $=2.0 \mathrm{~mm}$, spacing between ring $=1.0 \mathrm{~mm}$ )
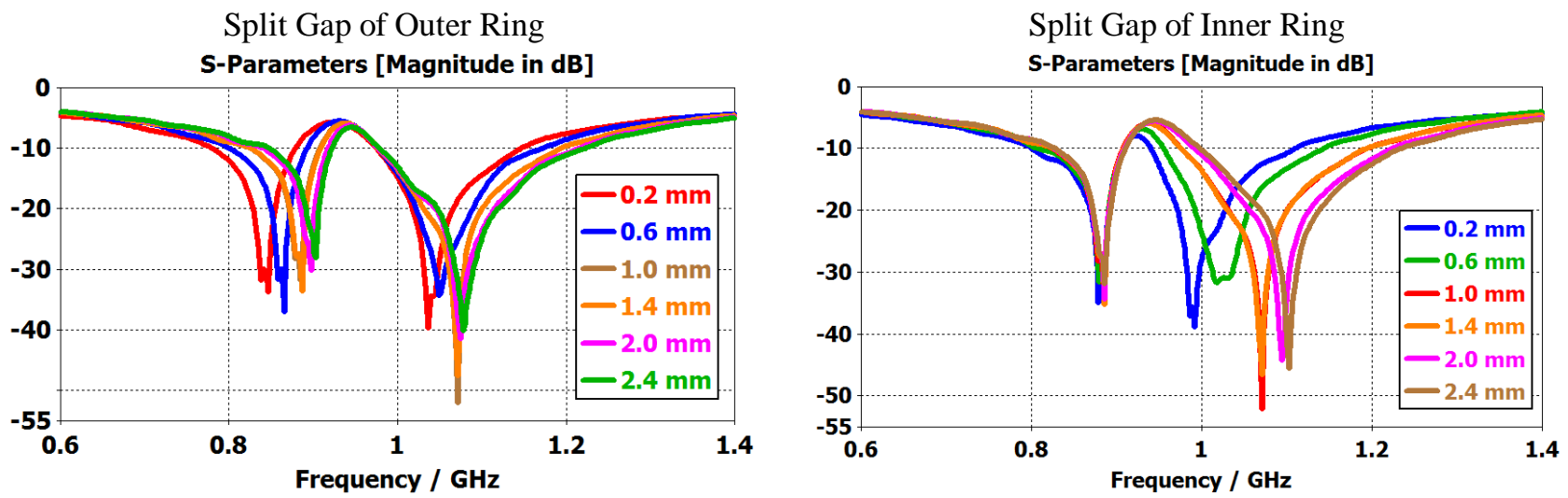

Figure 5. The simulated $S_{21}$ insertion loss result with varying split gap of outer ring and inner ring between $0.2-2.4 \mathrm{~mm}$

From Figure 5, the addition split gap of inner ring causes the higher resonant frequency of inner ring due to the reduction of capacitance between split gaps. The resonance frequency of outer ring remains unchanged at $0.48 \mathrm{GHz}$ due to no dimension change of outer ring. Despite no circumference changes when other parameters including width and spacing and split gap of outer ring are altered, the resonance frequency is varied. This is due to the minor effect of inductance and capacitive by varying the size of outer ring structure. The resonant frequency moves linearly with length in lambda. When the split gap changes from 0.2 to $2.4 \mathrm{~mm}$, the length in lambda changes from 0.46 to 0.5

The effect of spacing between rings on insertion loss is shown in Figure 6. The dimension of the inner ring is fixed while dimension of outer ring is unfixed following with change of spacing between rings. Increasing the spacing between rings will reduce the resonant frequency of outer ring due to increment of circumference of outer ring. However, the second resonant frequency is in the range between $1.06-1.08$ $\mathrm{GHz}$, despite no change in the dimension of inner ring due to reduction coupling between inner and outer ring.

Next, the effect of varying the width of the inner and outer ring is studied. The width of both rings is varied; position of spacing between two rings is fixed with the dimension of $1.0 \mathrm{~mm}$ and other parameter unchanged. The first resonant frequency is inversely linear proportional with width due to increment circumference size of the outer ring. The second resonance is remains unchanged due to no change outer circumference of the inner ring. However, when the width $=1 \mathrm{~mm}$ and spacing between ring $1 \mathrm{~mm}$, the second resonant frequency is altered to higher frequency. 

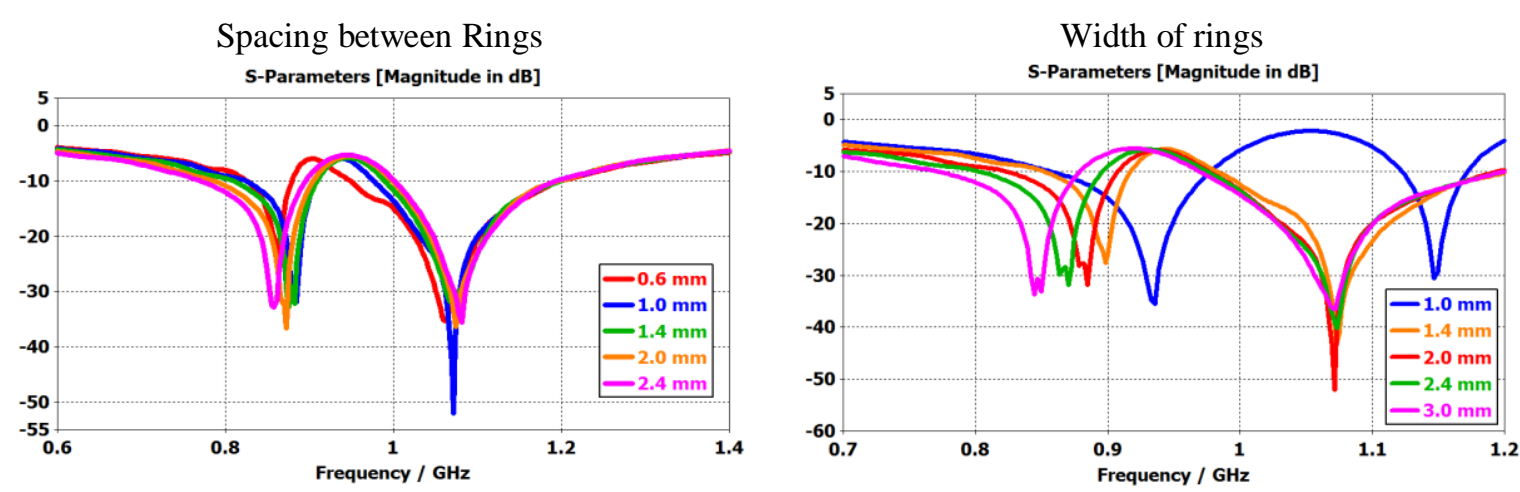

Figure 6. The simulated $S_{21}$ insertion loss result with varying spacing between rings and width of ring between $0.2-2.4 \mathrm{~mm}$

\subsection{Relationship between Parameter and Resonance Frequency}

The aim of analysis is to find the best dimension parameter between the split gap of the outer ring, split gap of the inner ring, spacing between the ring and width of both ring that carry out significantly change of resonant frequency. High changing of resonant frequency with the linear relationship with parameter dimension enables the chipless RFID decode ID number information with high accuracy and stable allocation. Based on Figure 7, spacing between ring and width of both ring parameters provide significantly effect on increasing circumference of outer ring. This effect causes the overall sign of ring structure become larger. The best parameter for decoding ID number information is split gap of the outer ring. By increasing the split gap of outer ring parameter, the change of circumference size is extremely small. When the split gap of the outer ring is varied from 0.6 to $2.4 \mathrm{~mm}$, the resonant frequency will change with linear from 0.85 to $0.90 \mathrm{GHz}$. The presence of capacitance element in the split gap of ring makes the length in lambda become smaller. When dimension of the split gap is reduced to $0.2 \mathrm{~mm}$, length in lambda of the outer ring becomes minimal which is 0.46 only.
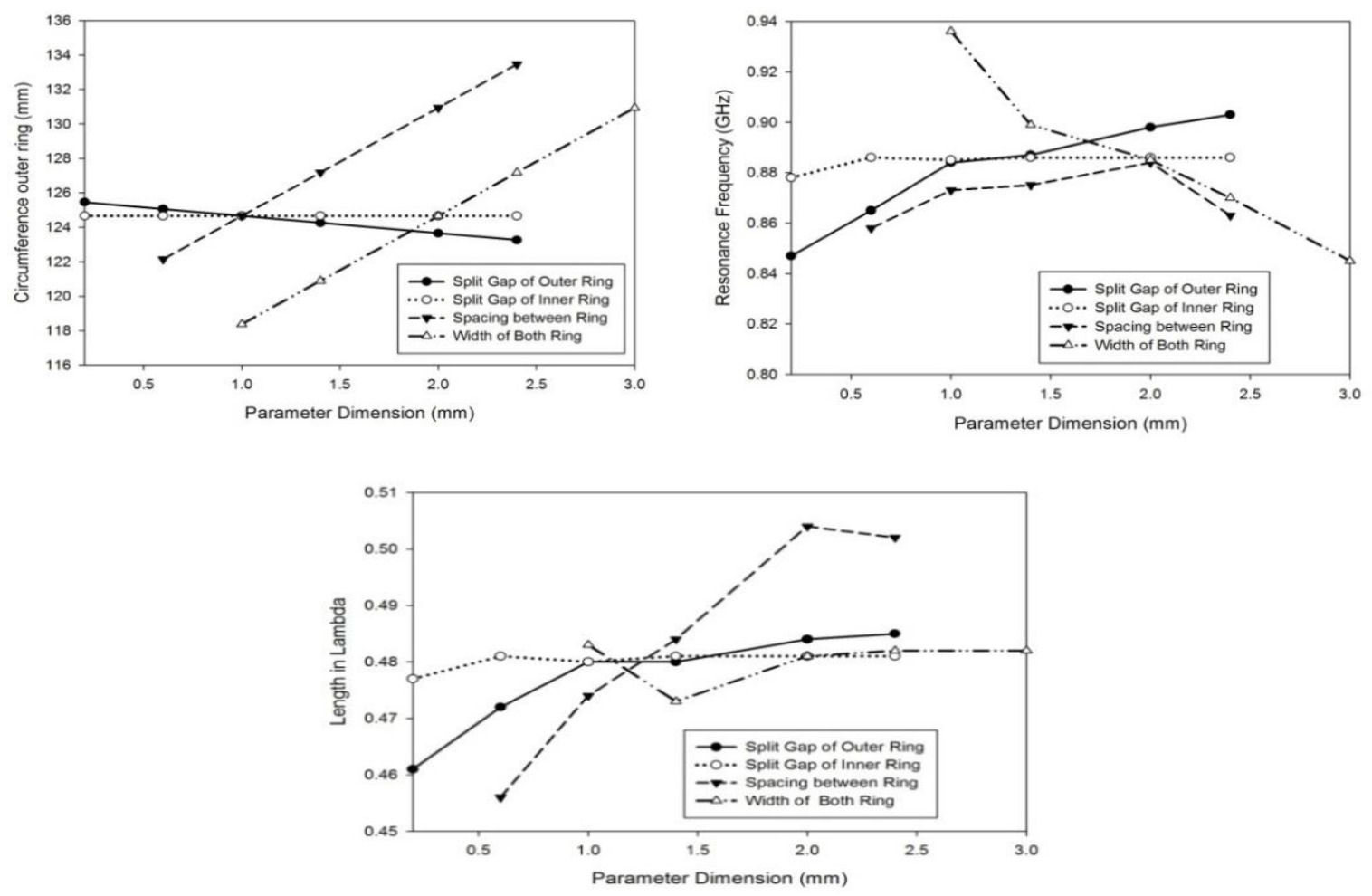

Figure 7. Relationship between dimension parameter and circumference of outer ring, relationship between length in lambda and resonance frequency of outer ring 
In Figure 8, a steady decrease of circumference can be observed as the split gap of outer ring moving inward. Other parameter dimension is not affecting the circumference due no dimension change of inner structure. Thus is important to examine a relationship between the split gap of the outer ring and second resonance frequency. The resonance frequency is seen to increase from 0.99 to $1.10 \mathrm{GHz}$ as split gap of the inner ring is increased from 0.2 to $2.4 \mathrm{~mm}$.
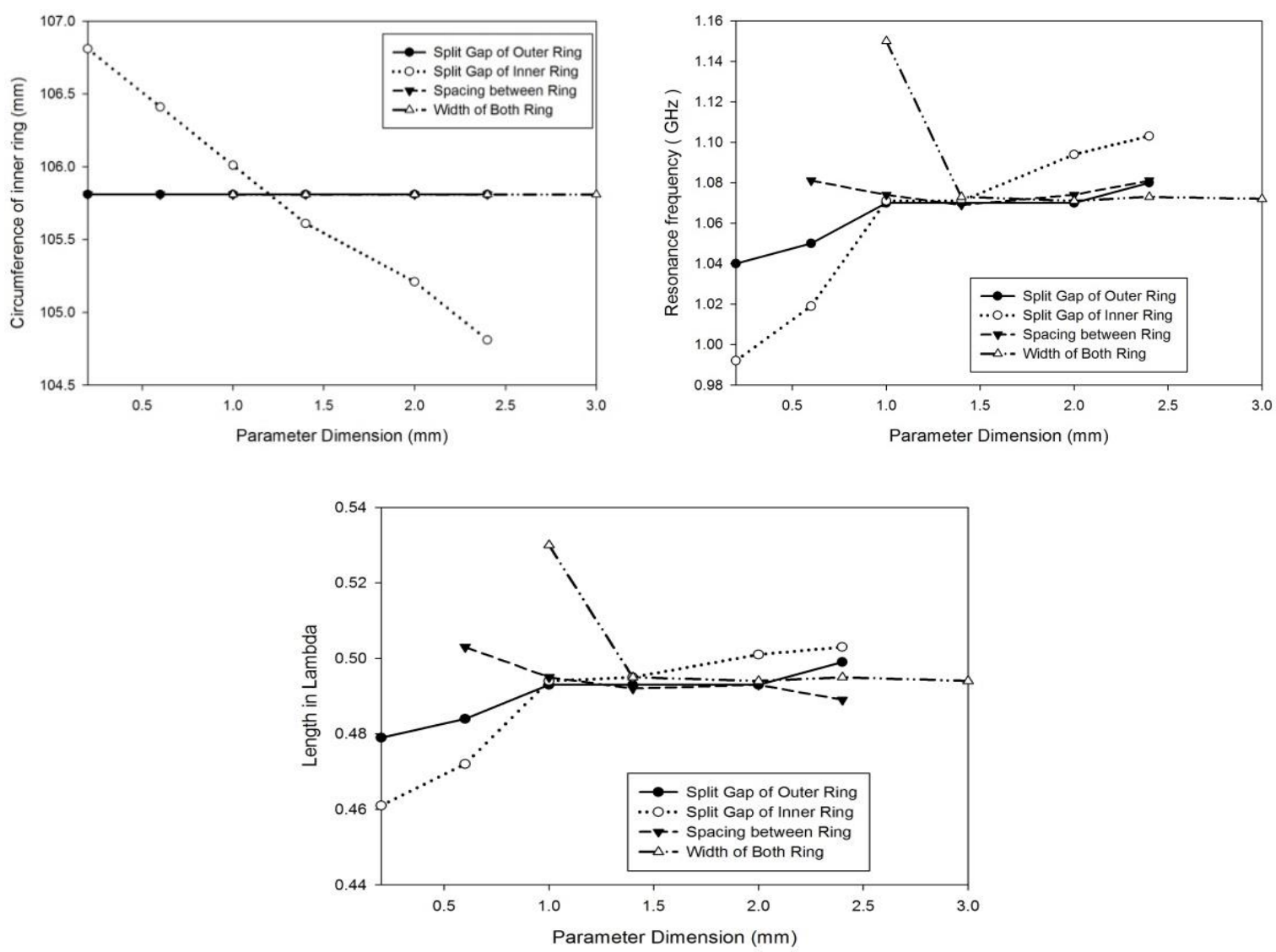

Figure 8. Relationship between dimension parameter and circumference of inner ring, relationship between length in lambda and resonance frequency of inner ring

\subsection{Frequency Position Technique for Data Encoding}

A frequency position technique is introduced to improve the amount of ID number information generated by a single ring resonator [25]. For data encoding, each ring structure represent two bit with four different resonance frequencies by varying the best parameter, split gap of ring structure. For example, by varying the split gap of outer ring from $1,2,3$ and $4 \mathrm{~mm}$, the outer ring structure resonate at four different band which are 0.87(00), 0.89(01), 0.91(10) and 0.93(11) GHz as shown in Figure 9. The second resonance of inner is slightly altered due to mutual coupling between two rings. However, all condition have bandwidth allocation of $100 \mathrm{MHz}$ to avoid overlapping between last condition of the outer ring (11) and initial condition of the inner ring (00). The chipless tag encoded bits $00,01,10$ and 11 by varying split gap of the inner ring from 1, 2, 3, $4 \mathrm{~mm}$. The first resonance is not influenced by adjusting the gap of the inner ring maintaining at $0.87 \mathrm{GHz}$. The single MCSRR structure is capable to encode from 0000-1111 ID number information's which about 16 frequency allocations. 

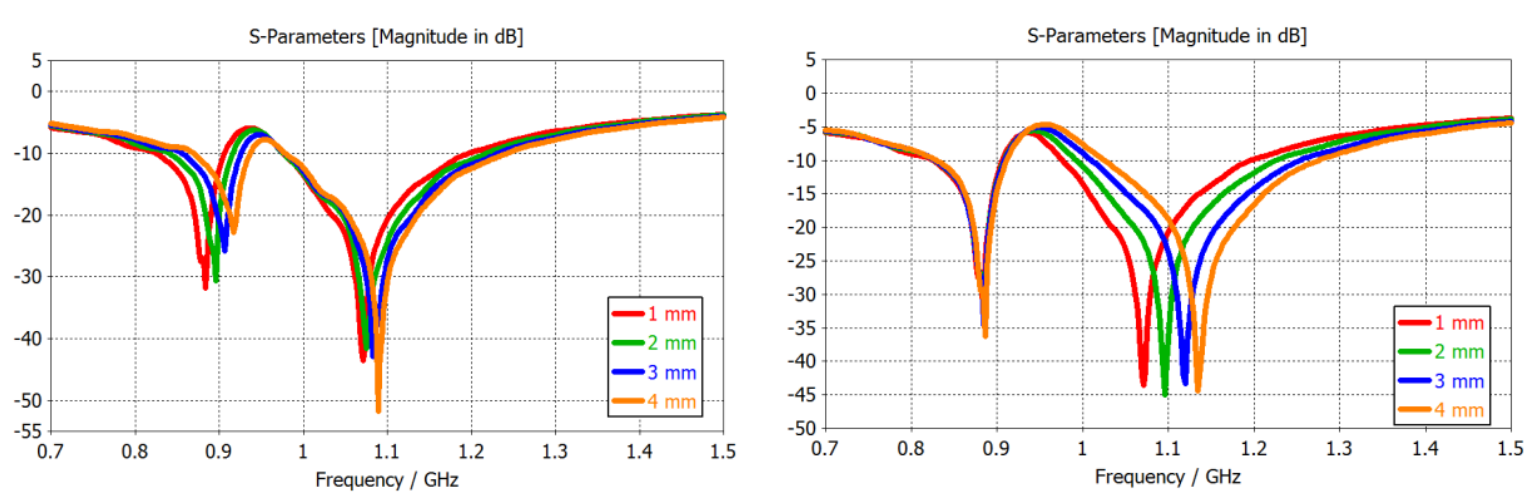

Figure 9. The simulated $S_{21}$ insertion loss result with varying split gap of outer ring (left) and split gap of the inner ring (right) from $1 \mathrm{~mm}$ to $4 \mathrm{~mm}$

\subsection{Simulation and Measurement Result of 10 bit Chipless RFID with Five MCSRR Resonators}

A 10 bit MCSRR chipless RFID with 5 rings resonator is designed and fabricated using flexible PET substrate. The chipless RFID 1024 ID number information is encoded by swapping parameter of the split gap of both ring. Figure 9 shows the simulation and measurement is valid with the consistent trend with one another. The fabrication using commercial electronic cutting tool considers limitation in term of dimension sensitivity which structure only fabricated above $1 \mathrm{~mm}$. The MCSRR structure demonstrates the potential to be used to design high capacity data and miniaturization size by adding bit condition using machine with reduced sensitivity.
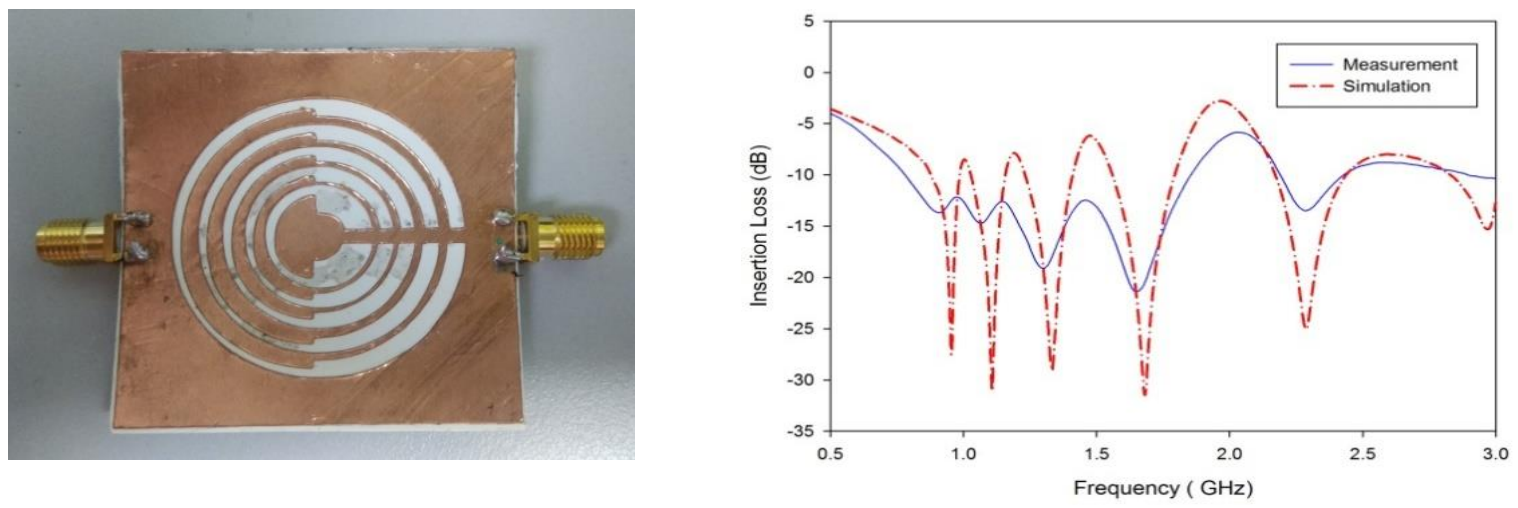

Figure 10. a) Fabricated 10 bit MCSRR chipless RFID tag with 5 resonator using PET substrate b) Simulation and measurement result of five MCSRR structure

\section{CONCLUSION}

The chipless RFID tag using modified Complementary Split Ring Resonator (MCSRR) with DW miniaturizes size and increase data capacity of with reducing effective length of the resonator and range frequency between two resonators. The MCSRR structure with WD provides less size about $17 \%$ compared with conventional MCSRR structure. The single MCSRR resonator with different width only requires a frequency range of $12 \%$ of CSRR resonator. The best parameter for decoding ID information is split gap of both ring compare among spacing between ring and width ring. When the split gap of the outer ring is varied from 0.2 to $2.4 \mathrm{~mm}$, the resonant frequency will change with linear from 0.85 to $0.90 \mathrm{GHz}$. The second resonance is seen to increase from 0.99 to $1.10 \mathrm{GHz}$ as split gap of the inner ring is increased from 0.2 to $2.4 \mathrm{~mm}$.

For future work, the maximum number of resonators and the number of allocation band is investigated to maximize number of ID information. For example, 10 resonators with nine allocation frequency bands are able to generate one million of ID information by altering sensitivity of the parameter to $0.01 \mathrm{~mm}$. At the same time, overlapping between resonances and producing stable ID number information is critical consideration for designing chipless RFID tag based frequency domain. 


\section{ACKNOWLEDGEMENTS}

The authors thank the Ministry of Education (MOE) for supporting the research work and Research Management Centre (RMC), School of Postgraduate Studies (SPS) and Communication Engineering Department, Faculty of Electrical Engineering (FKE), Universiti Teknologi Malaysia (UTM), Johor Bahru, for the support of the research under Grant Nos. 4F360, 05H35, $14 \mathrm{~J} 87$ and 4F277. The authors would also like to acknowledge all members of Advanced RF and Microwave Research Group (ARFMRG).

\section{REFERENCES}

[1] A. Attaran and R. Rashidzadeh, "Chipless Radio Frequency Identification Tag for IoT Applications," in IEEE Internet of Things Journal, vol. 3, no. 6, pp. 1310-1318, Dec. 2016.

[2] Jalil M E, Rahim M K A, Samsuri N A, et al. "Flexible printed chipless RFID tag using metamaterial-split ring resonator[J]". Applied Physics A, 2016, 122(4):1-8.

[3] Linlin Zheng, S. Rodriguez, Lu Zhang, Botao Shao and Li-Rong Zheng, "Design and implementation of a fully reconfigurable chipless RFID tag using Inkjet printing technology," 2008 IEEE International Symposium on Circuits and Systems, Seattle, WA, 2008, pp. 1524-1527.

[4] S. Preradovic, I. Balbin, N. C. Karmakar and G. F. Swiegers, "Multiresonator-Based Chipless RFID System for Low-Cost Item Tracking," in IEEE Transactions on Microwave Theory and Techniques, vol. 57, no. 5, pp. 1411-1419, May 2009. 1.

[5] S. Preradovic and N. C. Karmakar, "Chipless RFID: Bar Code of the Future," in IEEE Microwave Magazine, vol. 11, no. 7, pp. 87-97, Dec. 2010.

[6] S. Harma, V. P. Plessky, C. S. Hartmann and W. Steichen, "Z-path SAW RFID tag," in IEEE Transactions on Ultrasonics, Ferroelectrics, and Frequency Control, vol. 55, no. 1, pp. 208-213, January 2008.

[7] S. Genovesi, F. Costa, A. Monorchio and G. Manara, "Chipless RFID Tag Exploiting Multifrequency Delta-Phase Quantization Encoding," in IEEE Antennas and Wireless Propagation Letters, vol. 15, pp. 738-741, 2016. 1.

[8] Mohd Ezwan Bin Jalil, Mohammad Kamal A. Rahim, Noor Asmawati Samsuri,Raimi Dewan, "Multi-resonator Using Complementary Split Ring Resonator for Chip-Less RFID Application" Theory and Applications of Applied Electromagnetics, APPEIC 2014,215-221,2015.

[9] M. E. Jalil, Mohammad Kamal A Rahim, Noor Asmawati Samsuri and R. Dewan, "Chipless RFID Tag based on Meandered Line Resonator", 2014 IEEE Asia-Pacific Conference on Applied.

[10] G. S. Vardhan, N. Sivadasan and A. Dutta, "QR-Code Based Chipless RFID System for Unique Identification," 2016 IEEE International Conference on RFID Technology and Applications (RFID-TA), Foshan, 2016, pp. 35-39. doi: 10.1109/RFID-TA.2016.7750744.

[11] S. Preradovic and N. C. Karmakar, "Design of Fully Printable Planar Chipless RFID Transponder with 35-Bit Data Capacity," 2009 European Microwave Conference (EuMC), Rome, 2009, pp. 013-016.

[12] A. Vena, E. Perret and S. Tedjini, "Chipless RFID Tag Using Hybrid Coding Technique," in IEEE Transactions on Microwave Theory and Techniques, vol. 59, no. 12, pp. 3356-3364, Dec. 2011

[13] M. S. Bhuiyan, A. Azad and N. Karmakar, "Dual-Band Modified Complementary Split Ring Resonator (MCSRR) Based Multi-Resonator Circuit for Chipless RFID Tag," 2013 IEEE Eighth International Conference on Intelligent Sensors, Sensor Networks and Information Processing, Melbourne, VIC, 2013, pp. 277-281.

[14] S. Painam and C. Bhuma, "Miniaturizing a Microstrip Antenna Using Metamaterials and Metasurfaces [Antenna Applications Corner]," in IEEE Antennas and Propagation Magazine, vol. 61, no. 1, pp. 91-135, Feb. 2019. 1.

[15] C. Tan, Y. Wang, Z. Yan, X. Nie, Y. He and W. Chen, "Superconducting Filter Based on Split-Ring Resonator Structures," in IEEE Transactions on Applied Superconductivity, vol. 29, no. 4, pp. 1-4, June 2019, Art no. 1500404

[16] N. Zhang, W. X. Jiang, H. F. Ma, W. X. Tang and T. J. Cui, "Compact High-Performance Lens Antenna Based on Impedance-Matching Gradient-Index Metamaterials," in IEEE Transactions on Antennas and Propagation, vol. 67, no. 2, pp. 1323-1328, Feb. 2019.

[17] A. Ebrahimi, W. Withayachumnankul, S. Al-Sarawi and D. Abbott, "High-Sensitivity Metamaterial-Inspired Sensor for Microfluidic Dielectric Characterization," in IEEE Sensors Journal, vol. 14, no. 5, pp. 1345-1351, May 2014.

[18] K. Li, C. Zhu, L. Li, Y. Cai and C. Liang, "Design of Electrically Small Metamaterial Antenna With ELC and EBG Loading," in IEEE Antennas and Wireless Propagation Letters, vol. 12, pp. 678-681, 2013.

[19] B. Zarghooni, A. Dadgarpour and T. A. Denidni, "Greek-Key Pattern as a Miniaturized Multiband Metamaterial Unit-Cell," in IEEE Antennas and Wireless Propagation Letters, vol. 14, pp. 1254-1257, 2015.

[20] K. Sun, S. Han, J. H. Choi and J. K. Lee, "Miniaturized Active Metamaterial Resonant Antenna With Improved Radiation Performance Based on Negative-Resistance-Enhanced CRLH Transmission Lines," in IEEE Antennas and Wireless Propagation Letters, vol. 17, no. 7, pp. 1162-1165, July 2018.

[21] C. Y. Tan and K. T. Selvan, "A Performance Comparison of a Ku-Band Conical Horn with an Inserted ConeSphere with Horns with an Integrated Dielectric Lens and Metamaterial Loading [Antenna Designer's Notebook]," in IEEE Antennas and Propagation Magazine, vol. 53, no. 5, pp. 115-122, Oct. 2011.

[22] A. K. Horestani, C. Fumeaux, S. F. Al-Sarawi and D. Abbott, "Split Ring Resonators With Tapered Strip Width for Wider Bandwidth and Enhanced Resonance," in IEEE Microwave and Wireless Components Letters, vol. 22, no. 9, pp. 450-452, Sept. 2012. 
[23] J. D. Baena et al., "Equivalent-Circuit Models for Split-Ring Resonators and Complementary Split-Ring Resonators Coupled to Planar Transmission Lines," in IEEE Transactions on Microwave Theory and Techniques, vol. 53, no. 4, pp. 1451-1461, April 2005.

[24] Salvado, R.; Loss, C.; Gonçalves, R.; Pinho, P. "Textile Materials for the Design of Wearable Antennas: A Survey". Sensors 2012, 12, 15841-15857.

[25] M.E. Jalil, M.K.A. Rahim, N.A. Samsuri, R. Dewan, "Flexible Printed Chipless RFID Tag Using MetamaterialSplit Ring Resonator”. Appl. Phys. A 122, 348 (2016).

\section{BIOGRAPHIES OF AUTHORS}
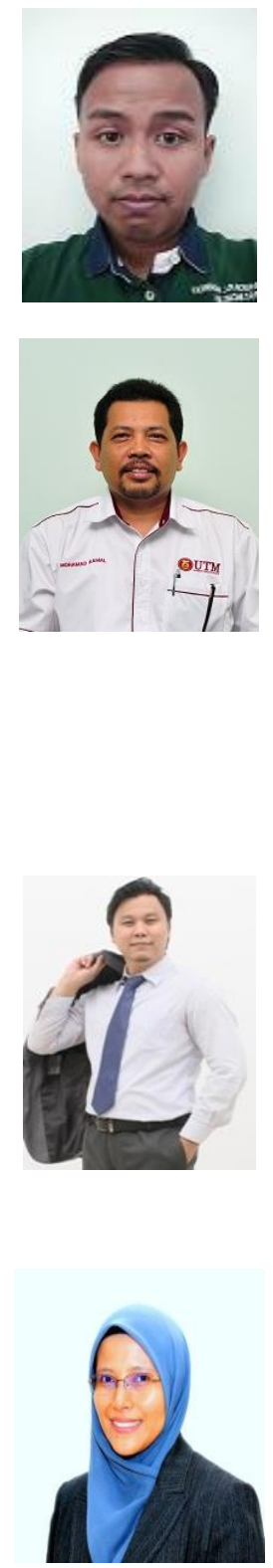

Mohd Ezwan Bin Jalil received the B.Eng. (Hons) in Electrical Engineering (Telecomunication) from Universiti Teknologi Malaysia in 2011 and, the MSc. Electrical Engineering from Universiti Teknologi Malaysia in 2014. Currently, he is a PhD student in Electrical Engineering under Antenna and RadioFrequency Microwave Group of School of Electrical Engineering, Universiti Teknologi Malaysia. His interest includes a compact and miniaturized wearable antenna, RFID antenna, chipless RFID@RF barcode, on-body measurement, Artificial Magnetic Conductor (AMC), Frequency Selective Surface (FSS), Metamaterials and microwave Absorber.

Mohamad Kamal A Rahim received the B Eng. degree in Electrical and Electronic Engineering from University of Strathclyde, UK, in 1987. In 1989, he joined the Department of Communication Engineering, Faculty of Electrical Engineering Universiti Teknologi Malaysia Kuala Lumpur as an Assistant Lecturer A. He obtained his M.Eng Science from University of New South Wales Australia in 1992 and $\mathrm{PhD}$ degrees in Electrical Engineering from University of Birmingham UK in 2003. After he received his Master he was appointed as a Lecturer at Faculty of Electrical Engineering. In 2005 he was appointed as a senior lecturer and in 2007 he was appointed as Assoc Professor at the faculty. Now he is the Professor in RF and Antenna at Faculty of Electrical Engineering Universiti Teknologi Malaysia. His research interest includes the areas of design of Dielectric resonator antennas, microstrip antennas, small antennas, microwave sensors, RFID antennas for readers and tags, Multi-function antennas, microwave cicuits, EBG, artificial magnetic conductors, metamaterials, phased array antennas, computer aided design for antennas and design of millimeter frequency antennas. He has published over 200 articles in journals and conference papers.

Dr. Osman bin Ayop has received his PHD in Electrical Engineering (2016), master in Electrical Electrical (2010) and first degree in Electrical Engineering -Telecommunication (2007) from Universiti Teknologi Malaysia. His research interests are in the field of antennas, propagation, and also metamaterials. He has been published numerous of journals, proceedings, research books, and book chapters. He also won several university and national awards related to his research works. He has been appointed as a reviewer for several national/international journals and conferences. He is also an active researcher in Advanced RF and Antenna Research Group (ARFMRG) and has been participated in a lot of courses, seminars, exhibition etc. He has been appointed as a Senior Lecturer in Faculty of Electrical Engineering UTM from 5 April 2016 until today.

Noor Asmawati Samsuri received the B.Eng. (Hons) in Electrical-Telecommunication Engineering from Universiti Teknologi Malaysia in 2001, the MSc. in Digital Communications System from Loughborough University, UK in 2004 and the Ph.D. in Electronic and Electrical Engineering from Loughborough University, UK in 2009. She is presently a Senior Lecturer in the Faculty of Electrical Engineering, Universiti Teknologi Malaysia. Her research interests include wearable antennas including the interaction with human body and metallic items, implantable antenna for medical telemetry, and Specific Absorption Rate (SAR). During her carrier, she has been authored or co-authored several technical papers and book chapters related to her research interests. She has also been appointed as a reviewer for several journal papers at National and International level. Noor Asmawati Samsuri is a member of Board of Engineer Malaysia (BEM) and a member of IEEE (MIEEE), and is currently supervising a $\mathrm{PhD}$, Master and Undergraduate students. 